\title{
Effect of PON1 on dichlorvos toxicokinetics
}

\author{
Na-Na Wang, Li Yuan, Heng Dai, Zhen-Kun Han, Min Zhao
}

Emergency Department, Shengjing Hospital of China Medical University, Shenyang, China

\section{Correspondence to} Zhao Min, Emergency Department, China Medical University, Shenyang, China; zhaom@sj-hospital.org

Accepted 20 March 2010 Published Online First 26 June 2010

\section{UNLCKAD}

This paper is freely available online under the BMJ Journals unlocked scheme, see http:// emj.com/site/about/unlocked. xhtml

\section{ABSTRACT \\ Objectives To provide toxicokinetic and clinical evidence of the hydrolytic effect of paraoxonase-1 (PON1) on acute organophosphate poisoning in rats.}

Methods 40 male Wistar rats were randomised into four equal groups. Dichlorvos administration group (A group) underwent dichlorvos injection (dissolved in corn oil) using intraperitoneal (ip) dose of $10 \mathrm{mg} / \mathrm{kg}$. PON1 pretreatment group (B group) was injected with PON1 in the tail vein (intravenous), dose $9600 \mathrm{U} / \mathrm{kg}, 30$ min prior to dichlorvos administration. In the treatment group ( $C$ group), atropine $0.05 \mathrm{mg} / \mathrm{kg}$ and pyraloxime chloride (PAM-CI) $120 \mathrm{mg} / \mathrm{kg}$ were injected intravenously within 2 min after dichlorvos administration. Finally, in the co-treatment group (D group), PON1 was injected intravenously with a dose of $9000 \mathrm{U} / \mathrm{kg} 30 \mathrm{~min}$ prior to dichlorvos administration; atropine $0.05 \mathrm{mg} / \mathrm{kg}$ and PAMCl $120 \mathrm{mg} / \mathrm{kg}$ were injected intravenously within $2 \mathrm{~min}$ after dichlorvos administration. Blood was collected after administration. Plasma dichlorvos concentration was detected by liquid chromatography-mass spectra (LC-MS) method and clinical signs were observed. Toxicokinetic parameters were calculated in a statistical moment model.

Results AUC $(0 \rightarrow \infty)$ in group B was statistically different from that in groups $A$ and $C(p<0.05)$, while it was not different from group $D(p>0.05)$; there was no statistical difference between group $A$ and group $C$ ( $p>0.05)$. The statistical results of $\mathrm{Cmax}$ were the same as those of AUC $(0 \rightarrow \infty)$. There were no differences of MRT between four groups ( $p>0.05)$. Clinical signs can be improved by PON1 and atropine + PAM-Cl, and co-treatment can relieve signs more effectively. Conclusion PON1 can decrease the amount of dichlorvos that entered the blood, lowered the peak concentration and relieved clinical signs.

Serum paraoxonase-1 (PON1) is an A-esterase that is associated with high-density lipoprotein (HDLs). The products of PON1 gene exist widely in mammals, with the highest activity in liver and blood. It is involved in the detoxification of organophosphate insecticides, such as chlorpyrifos oxon, diazoxon, paraoxon and dichlorvos. ${ }^{12}$ As a result, it is considered to have great significance in the detoxication of organophosphate compounds. Therefore, PON1 may prevent tissue damage from organophosphate toxicity, especially in the central nervous system. There have been studies designed to evaluate the protective effect of PON1 to organophosphates in vitro or by measuring inhibition of acetyl cholinesterase in different tissues, but studies on organophosphate concentration changes in vivo are rare. ${ }^{3-5}$ In the present study, purified rabbit serum PON1 was administered to rats intravenously and concentration of dichlorvos in blood was detected at different time points to analyse the effect of PON1 on toxicokinetics of dichlorvos.

\section{MATERIALS AND METHODS \\ Material}

Dichlorvos ( $>99.5 \%$ pure) was obtained from Tianjin Agriculture Co., Ltd; acetonitrile, indomethacin and methanoic acid (chromatographic pure) were homemade reagents.

Clean grade male Wistar rats, weighing 250-300 g, were obtained from Beijing Vital River Experimental Animal Co., Ltd. The animals were fed ad libitum in the experiment.

ÄKTA purifier automatic chromatography was manufactured by GE Company (Bridgeport, Connecticut, USA). TSQ Quantum Ultra, produced by Thermo Finnigan (San Jose, California, USA). Eppendorf 5417-R refrigerated centrifuge was manufactured by Eppendorf Company (Hamburg, Germany).

\section{Dose schedule and sample collection}

40 male Wistar rats were randomised into four equal groups. The dichlorvos administration group (A group) underwent dichlorvos injection (dissolved in corn oil) using intraperitoneal (ip) dose of $10 \mathrm{mg} / \mathrm{kg}$. The PON1 pretreatment group (B group) was injected with PON1 in the tail vein (intravenous), dose $9600 \mathrm{U} / \mathrm{kg}, 30 \mathrm{~min}$ prior to dichlorvos administration $(10 \mathrm{mg} / \mathrm{kg}$ ip). In the treatment group (C group), atropine $0.05 \mathrm{mg} / \mathrm{kg}$ and pyraloxime chloride (PAM-CI) $120 \mathrm{mg} / \mathrm{kg}$ were injected intravenously within $2 \mathrm{~min}$ after dichlorvos administration (10 mg/kg ip). Finally, in the co-treatment group (D group), PON1 was injected intravenously in a dose of $9000 \mathrm{U} / \mathrm{kg}$ $30 \mathrm{~min}$ prior to dichlorvos administration $(10 \mathrm{mg} /$ $\mathrm{kg}$ ip); atropine $0.05 \mathrm{mg} / \mathrm{kg}$ and PAM-CI $120 \mathrm{mg} / \mathrm{kg}$ were injected intravenous within $2 \mathrm{~min}$ after dichlorvos administration.

Blood of $0.2 \mathrm{ml}$ was collected at $3 \mathrm{~min}, 5 \mathrm{~min}$, $10 \mathrm{~min}, 20 \mathrm{~min}, 30 \mathrm{~min}, 1 \mathrm{~h}, 2 \mathrm{~h}, 4 \mathrm{~h}$ and $6 \mathrm{~h}$ after administration from the eye veins. Blood was centrifuged at $5000 \mathrm{r}$ for $3 \mathrm{~min}$ and the supernatant was collected and stored in $-80^{\circ} \mathrm{C}$ for dichlorvos detection.

Clinical signs after dichlorvos poisoning were observed. According to Gaidukov, ${ }^{6}$ all clinical signs noted following dichlorvos intoxication were categorised to mild, moderate or severe reactions. Mild reactions were characterised by straub tail and/or ataxia and/or diarrhoea. Moderate reactions consisted of, in addition, decreased motor activity and/or dyspnoea, while animals with severe reactions exhibited ventral position and/or tremors as well. The overall reactions observed following dichlorvos intoxication were scored using semiquantitative grading of five grades $(0-4)$, taking into 
consideration the severity of the reactions $(0=$ no reactions, $1=$ mild reactions, $2=$ moderate reactions, $3=$ severe reactions, $4=$ mortality). Because there were no deaths in the experiment, no rats scored 4 .

\section{Purification of rabbit serum P0N1}

Paraoxonase was purified from rabbit serum as previously described in detail. ${ }^{7}$ The collected protein was subjected to centrifugal ultrafiltration on centrpuls YM-10 (Millipore, Billerica, Massachusetts, USA) so as to concentrate to $>3000 \mathrm{U} / \mathrm{ml}$. The enzyme was dissolved in buffer solution $(136 \mathrm{mM} \mathrm{NaCl}$, $0.1 \mathrm{mM} \mathrm{CaCl}_{2}$ ) for injection before usage.

\section{LC-MS method}

Sample preparation

Plasma aliquot of $50 \mu \mathrm{l}$ was added to $2.5 \mu \mathrm{l}$ of the internal standard indomethacin solutions that was prepared in methanol of $50 \mathrm{ng} / \mathrm{ml}$. Then, acetonitrile $(100 \mu \mathrm{l})$ was added to the mixture. The resulting mixture was vortex-mixed for $1 \mathrm{~min}$ and then centrifuged at $12000 \mathrm{r}$ for $5 \mathrm{~min}$. The supernatant was filtered through a $0.45-\mu \mathrm{m}$ Millex ${ }^{\circledR}-\mathrm{LH}$ filter, and $20 \mu \mathrm{l}$ of the filtrate was injected into the LC-APCI-MS.

\section{LC-MS condition}

The HPLC analysis was performed on a Diamonsil $\mathrm{C}_{18}$ column $(150 \times 4.6 \mathrm{~mm}$ inside diameter, $5 \mu \mathrm{m}$.) equipped with an phenomenex $\mathrm{C}_{18}$ guard column ( $4 \times 3.0 \mathrm{~mm}$ inside diameter) at room temperature. Fluid phase was used with solvent consisting of acetonitrile-water-methanoic acid (90:10:0.2, v/v/v) at a flow rate of $0.45 \mathrm{ml} / \mathrm{min}$. The solutions were filtered through a $0.45 \mu \mathrm{m}$ Millex ${ }^{\circledR}$-LH filter before use.

A Thermo Finnigan TSQ Quantum Ultra tandem mass spectrometer equipped with an APCI interface operated in the positive ion mode. The capillary voltage was set to $4.2 \mathrm{kV}$. The capillary temperature was $270^{\circ} \mathrm{C}$, and the desolvation temperature was $420^{\circ} \mathrm{C}$. Nitrogen was used as desolvation gas (pressure $30 \mathrm{Arb}$ ) and assist gas (pressure $5 \mathrm{Arb}$ ), and argon was used as collision gas at a pressure of $1.2 \mathrm{mTorr}$. Detection was performed in selected reaction monitoring (SRM) mode. The collision-induced dissociation voltages were $23 \mathrm{eV}$ (dichlorvos) and $44 \mathrm{eV}$ (indomethacin), respectively. Ionic reaction for quantitative analysis was $\mathrm{m} / \mathrm{z} 221 \rightarrow \mathrm{m} / \mathrm{z} 109$ (dichlorvos) and $\mathrm{m} / \mathrm{z} 358 \rightarrow \mathrm{m} / \mathrm{z} 111$ (indomethacin), respectively. Scan time was 0.3 s. $^{8}$

Following analysis by an LC-APCI-MS system, the retention time for dichlorvos was $4.07 \mathrm{~s}$, and that for indomethacin was $4.92 \mathrm{~s}$ (figure 1).

\section{Linearity}

Added dichlorvos standards to blank plasma detected the ratio of peak area of $6 \mu \mathrm{g} / \mathrm{ml}, 5 \mu \mathrm{g} / \mathrm{ml}, 2 \mu \mathrm{g} / \mathrm{ml}, 1 \mu \mathrm{g} / \mathrm{ml}, 0.5 \mu \mathrm{g} / \mathrm{ml}$ and $0.2 \mu \mathrm{g} / \mathrm{ml}$ of dichlorvos to internal standard peak area.

With defined dichlorvos standards peak area as X-axis, ratio of dichlorvos standards peak area to internal standard peak area as Y-axis, we got the regression line of dichlorvos: $Y=-0.0404282$ $+0.16048 * X, R^{2}=0.9945$.

The linearity was $0.2-6 \mu \mathrm{g} / \mathrm{ml}$.

\section{Statistics}

A statistical moment model was used to calculate toxicokinetics parameters for dichlorvos by $3 \mathrm{p} 97$ software. Statistical analyses were conducted using SPSS16.0 software.

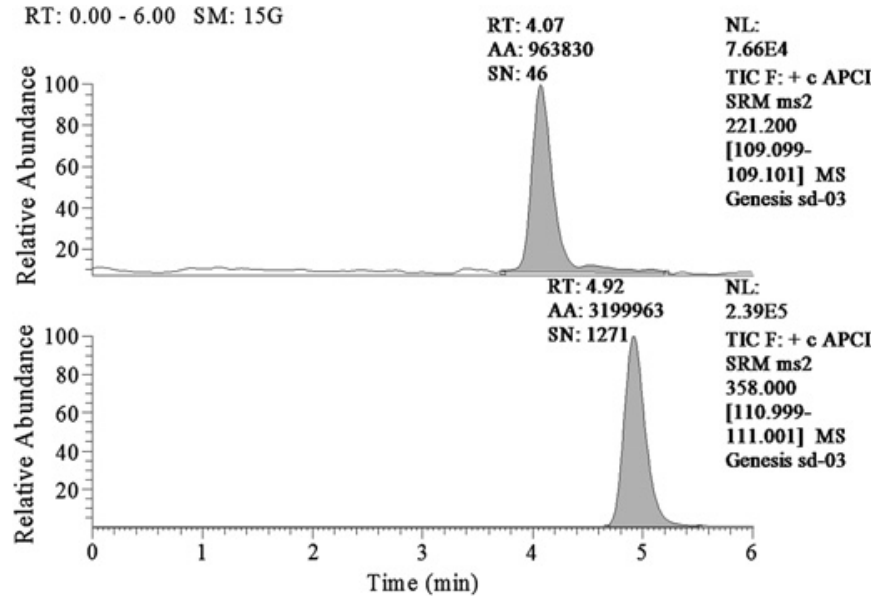

Figure 1 Blank blood with IS and dichlorvos standard. Dichlorvos was shown at $4.07 \mathrm{~min}$ (upper panel), and IS was shown at $4.92 \mathrm{~min}$ (lower panel).

\section{RESULTS}

\section{Toxicokinetics of dichlorvos}

\section{Dichlorvos concentration}

The concentrations of dichlorvos in $B$ group were statistically different from A group $(\mathrm{p}<0.05)$, while atropine + PAM-CI did not alter dichlorvos concentration statistically $(\mathrm{p}>0.05)$ (table 1$)$.

\section{Dichlorvos toxicokinetics parameters}

The toxicokinetics parameter differences between four groups were performed by ANOVA. There were no statistical differences between AUC $(0 \rightarrow \infty)$ of groups $A$ and $C$, but the effect of PON1 was obvious in groups B and D when compared with group A. There were no statistical differences between MRT $(0 \rightarrow \infty)$ of the four groups. Cmax was obtained by observing the peak concentrations in table 1 . The statistical result coincided with that of AUC $(0 \rightarrow \infty)$ (table 2 ).

\section{Clinical signs}

The clinical signs were alleviated by PON1, atropine+ PAM-CI and co-treatment, and the effect of PON1 was not different with atropine+ PAM-CI statistically. However, co-treatment achieved the best effect (table 3).

\section{DISCUSSION}

The $1 / 2 \mathrm{LD}_{50}\left(\mathrm{LD}_{50}, 18-20 \mathrm{mg} / \mathrm{kg}\right.$ by ip) of dichlorvos was selected so that the most severe signs of poisoning would be elicited but no death arose through preliminary experiment. The

Table 1 Time-dichlorvos concentration of four groups

\begin{tabular}{lllll}
\hline $\begin{array}{l}\text { Time } \\
(\mathbf{h})\end{array}$ & $\begin{array}{l}\text { A group } \\
(\mu \mathrm{g} / \mathrm{m})\end{array}$ & $\begin{array}{l}\text { B group } \\
(\mu \mathrm{g} / \mathrm{ml})\end{array}$ & $\begin{array}{l}\text { C group } \\
(\mu \mathrm{g} / \mathrm{ml})\end{array}$ & $\begin{array}{l}\text { D group } \\
(\mu \mathrm{g} / \mathrm{ml})\end{array}$ \\
\hline 0.05 & $1.84 \pm 0.85$ & $0.76 \pm 0.17^{*}$ & $1.83 \pm 0.40$ & $0.76 \pm 0.07^{*}$ \\
0.08 & $3.31 \pm 0.31$ & $1.22 \pm 0.13^{*}$ & $3.13 \pm 0.27$ & $1.33 \pm 0.21^{*}$ \\
0.17 & $5.36 \pm 0.63$ & $2.91 \pm 0.18^{*}$ & $5.28 \pm 0.55$ & $2.90 \pm 0.32^{*}$ \\
0.33 & $2.85 \pm 0.30$ & $1.57 \pm 0.26^{*}$ & $2.74 \pm 0.42$ & $1.54 \pm 0.05^{*}$ \\
0.5 & $1.93 \pm 0.26$ & $0.99 \pm 0.18^{*}$ & $1.87 \pm 0.34$ & $0.95 \pm 0.17^{*}$ \\
1 & $1.35 \pm 0.22$ & $0.64 \pm 0.08^{*}$ & $1.25 \pm 0.10$ & $0.64 \pm 0.10^{*}$ \\
2 & $1.09 \pm 0.21$ & $0.35 \pm 0.07^{*}$ & $1.05 \pm 0.16$ & $0.35 \pm 0.01^{*}$ \\
4 & $0.66 \pm 0.16$ & $0.23 \pm 0.01^{*}$ & $0.65 \pm 0.09$ & $0.23 \pm 0.03^{*}$ \\
6 & $0.37 \pm 0.06$ & $0.22 \pm 0.01^{*}$ & $0.35 \pm 0.02$ & $0.21 \pm 0.01^{*}$
\end{tabular}

All the data were expressed as mean \pm SD.

${ }^{*} p<0.01$, concentration data were compared with $A$ group by $t$ test. There were statistical differences between group $B$ and group $A$ and between group $C$ and group $A$ 
Table 2 Toxicokinetics parameters of dichlorvos

\begin{tabular}{llllr}
\hline Parameter & A group & B group & C group & \multicolumn{1}{c}{ D group } \\
\hline $\mathrm{AUC}(0 \rightarrow \infty)$ & $11.24 \pm 1.63$ & $4.25 \pm 0.41$ & $10.71 \pm 0.97$ & $4.67 \pm 0.99$ \\
$\left(\mu \mathrm{g} / \mathrm{ml}{ }^{*} \mathrm{~h}\right)$ & & & & \\
$\mathrm{MRT}(\mathrm{h})$ & $7.93 \pm 1.40$ & $8.50 \pm 2.05$ & $7.65 \pm 0.87$ & $13.89 \pm 5.80$ \\
$\mathrm{Cmax}(\mu \mathrm{g} / \mathrm{ml})$ & $5.36 \pm 0.63$ & $2.91 \pm 0.18$ & $5.28 \pm 0.55$ & $2.90 \pm 0.32$ \\
\hline
\end{tabular}

All the data were expressed as mean \pm SD.

dose is different from the larger dose exposures that occur in clinical situations and experimentally in vitro; however, it allow us to evaluate toxicokinetics of dichlorvos.

The results of the study suggested that PON1 can effectively decrease blood dichlorvos concentration, reduce the peak concentration of dichlorvos and lessen the amount that enters the blood. It is possible that a high degree of protection was provided by PON1 pretreatment in animals challenged with organophosphates by measuring cholinesterase activities in different tissues. ${ }^{10-12}$ Our results provide further direct evidence by showing changes in concentration with PON1 pre-treatment. We also compared the hydrolytic effect of PON1 with atropine + PAM, the most widely used therapy clinically. The results of the study show that atropine +PAM does not affect the metabolism of dichlorvos, which is consistent with the findings of a previous study. ${ }^{13}$ Co-treatment does not alter the impact of PON1 on dichlorvos concentrations, which implies that there is no interaction between PON1 and atropine+ PAM-CI; therefore, it is postulated that co-treatment may be feasible in the clinical treatment of human organophosphate-related toxicity.

We also investigated the clinical signs of the four groups. Decreased blood dichlorvos concentration in the PON1 pretreatment group resulted in better clinical outcome when compared with the dichlorvos administration group. At this dose, the PON1 effect is comparable to that of atropine+ PAM$\mathrm{CI}$, which is the most common antidotal treatment used clinically. In addition, another novel finding in our study was that the clinical signs were relieved the most by co-treatment. This may have important implications on the future treatment of organophosphates poisoning.

Interest in PON1 arises from the hypothesis that individuals with low serum activity of this enzyme would be expected to have a diminished ability to metabolise organophosphates. This hypothesis implies that serum PON1 has a pivotal role in the detoxification of the organophosphate. After the hypothesis was raised, some studies have been designed to evaluate the protective effect of PON1 by pretreating animals with PON1 before organophosphates administration. Such studies are needed before any definite inference can be drawn on the role that serum paraoxonase levels have in the protective effect on insecticides. However, in the treatment of human organophos-
Table 3 Clinical signs scores of four groups

\begin{tabular}{lllll}
\hline & Score & & & \\
\cline { 2 - 5 } Group & $\mathbf{0}$ & $\mathbf{1}$ & $\mathbf{2}$ & $\mathbf{3}$ \\
\hline A group & 0 & 0 & 5 & 5 \\
B group & 0 & 2 & 7 & 1 \\
C group & 0 & 5 & 5 & 0 \\
D group & 2 & 6 & 2 & 0 \\
\hline
\end{tabular}

Ridit analysis was used to analyse the differences between the data of clinical signs scores of four groups, ${ }^{9}$ where $p<0.05$ was regarded as significant.

phate-related toxicity, antidotes are administered after exposure, so further investigations of PON1 should be conducted with PON1 administration after organophosphate exposure on the theoretical basis of protective function.

In conclusion, PON1 can hydrolyse organophosphates in vivo and improve clinical signs of organophosphate toxicity. The use of PON1 in organophosphates poisoning requires further investigations.

Funding National Natural Science Foundation of China (No. 30671778) and Technology of the Education Department of Liaoning Province (No. 05L480).

Competing interests None.

Provenance and peer review Not commissioned; externally peer reviewed.

\section{REFERENCES}

1. Rochu D, Chabri'ere E, Masson P. Human paraoxonase: a promising approach for pre-treatment and therapy of organophosphorus poisoning. Toxicology 2007;233:47-59.

2. Costa LG, Cole TB, Furlong CE. Polymorphisms of paraoxonase (PON1) and their significance in clinical toxicology of organophosphates. J Toxicol Clin Toxicol 2003; 41:37-45.

3. Aharoni A, Gaidukov L, Khersonsky 0, et al. The 'evolvability' of promiscuous protein functions. Nat Genet 2005;37:73-6.

4. Khersonsky 0, Tawfik DS. Structure-reactivity studies of serum paraoxonase PON suggest that its native activity is lactonase. Biochemistry 2005;44:6371-82

5. Maxwell DM, Brecht KM, Chang F, et al. Toxicodynamic modelling of highly toxic organophosphorus compound. J Mol Neurosci 2006;30:129-31.

6. Leonid G, Dganit B, Shiri Y, et al. In vivo administration of BL-3050: highly stable engineered PON1-HDL complexes. BMC Clin pharmacol 2009;9:1-13.

7. Zhao M, Cui Y, Yuan L. Extraction and purification of rabbit serum paraoxonase. J China Medical University 2009;38:490-2.

8. Shigeaki I, Takeshi S, Hiroyasu M, et al. Rapid simultaneous determination for organophosphorus pesticides in human serum by LC-MS. J Pharm Biomed Anal 2007;:44:258-64.

9. Wu S, Ye DQ. Implementation of ridit analysis in single unidirectional ordered data of multiple groups in SPSS. Chinese Health Statistics 2006;23:554.

10. Costa LG, McDonald BE, Murphy SD, et al. Serum paraoxonase and its influence on paraoxon and chlorpyrifos toxicity in rats. Toxicol Appl Pharmacol 1990;103:66-76.

11. Li WF, Costa LG, Furlong CE. Serum paraoxonase status: a major factor in determining resistance to organophosphates. J Toxicol Environ Health 1993; 40:337-46

12. Li WF, Furlong CE, Costa LG. Paraoxonase protects against chlorpyrifos toxicity in mice. Toxicol Lett 1995;76:219-26.

13. Xiong YQ, Zeng FD. Effect of neferine on toxicodynamics of dichlorvos for inhibiting rabbit cholinesterase. Acta Pharmacol Sin 2003:24:332-6. 